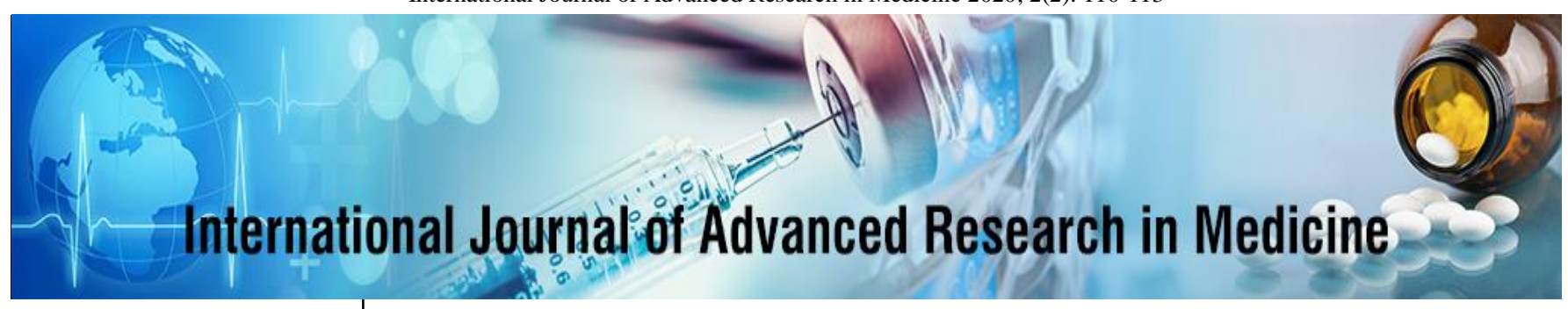

E-ISSN: 2706-9575

P-ISSN: 2706-9567

IJARM 2020; 2(2): 110-113

Received: 24-05-2020

Accepted: 27-06-2020

Dr. Arshdeep S Mann

MBBS, Medical Officer, Maan Hospital and Dialysis Center, Bathinda, Punjab, India

Dr. Harmanjot Singh MBBS, MD, Internal Medicine, ECFMG, Washington Medical Board, USA

Dr. Beant Singh Maan MBBS, MD, Internal Medicine, Medical Director, Maan Hospital and Dialysis Center, Bathinda, Punjab, India
Corresponding Author: Dr. Arshdeep S Mann MBBS, Medical Officer, Maan Hospital and Dialysis Center, Bathinda, Punjab, India

\section{To study the association of serum vitamin D levels with migraine in Indian rural female population: Case-control study}

\author{
Dr. Arshdeep S Mann, Dr. Harmanjot Singh and Dr. Beant Singh Maan
}

DOI: https://doi.org/10.22271/27069567.2020.v2.i2b.56

\begin{abstract}
Aim: To investigate the vitamin D serum levels of migraine patients and compared it with a control group.

Materials and Methods: The present case control study entitled was conducted in the Department of General Medicine during the period of I year. The study was performed on 150 female patients (case group $\mathrm{n}=100$ and matched control group $\mathrm{n}=50$ ) attended General Medicine outpatient department. 25-hydroxy vitamin $\mathrm{D}$ was analyzed with liquid chromatography-tandem mass spectrometry (LC/MS/MS) method.

Results: The Mean Age, Serum vitamin D level and BMI among cases and controls are as follows $(34.54 \pm 1.37,33.17 \pm 1.19),(13.12 \pm 0.98,13.41 \pm 0.19)$ and $(26.4 \pm 1.21,25.8 \pm 1.53) .58 \%$ of the cases had migraine frequency per month of more than 10 episodes and $36 \%$ of the cases shown that the pain last for 4-12 hours in a day.

Conclusion: The prevalence of vitamin D deficiency is roughly similar between cases and controls and between matching age groups. This suggests a high prevalence of vitamin D deficiency in both healthy population and migraine patients which implies a common underlying cause.
\end{abstract}

Keywords: Serum vitamin D, migraine headache, female.

\section{Introduction}

Vitamin D has been discovered at the beginning of the 20th century as a cure for rickets, a disease softening the bones in children ${ }^{[1,2]}$. Since then it has been established as an important factor in bone health, more specifically in bone metabolism and calcium homeostasis. Vitamin D is a lipid soluble vitamin which has a function of a hormone in the human body ${ }^{[3]}$. There are two forms of vitamin $\mathrm{D}$ present in nature: Vitamin D2 (ergocalciferol) and vitamin D3 (cholecalciferol) ${ }^{[2]}$.

Vitamin D is not only important in mineral homeostasis but it is also an anti-inflammatory hormone that can regulate immune responses, cell proliferation, and endothelial function ${ }^{[4}$, 5]. Also, vitamin D has a negative effect on proliferation of mast cells and can stimulate nitric oxide (NO) ${ }^{[6]}$ (a vasoactive substance that interacts with blood vessels). With these mechanisms, vitamin $\mathrm{D}$ has a potent role in cardiovascular disease ${ }^{[7]}$. Growing but conflicting evidence has shown a possible relationship between vitamin $\mathrm{D}$ and chronic or recurrent painful conditions such as migraine ${ }^{[8]}$.

There are no known causes of migraines that are consistent for all patients. However, there are some common causing factors that are found amongst migraines. Some of those factors are depicted as hyperexcitable brain that reacts stronger to stimuli, which happens due to an inflammation of the lining of the brain. Another factor is genetics, where people are more predisposed to changes in estrogen levels, weather changes, a disrupted sleep pattern, or red wine. (Evans \& Evans 2009) ${ }^{[9]}$.

As of today, there is no known cure for migraine headaches. However, there are a few possible treatments for the symptoms of this disorder. One study reported that $40 \%$ of migraine patients had vitamin D deficiency ${ }^{[10]}$. Two case-report studies have shown that treatment with vitamin $\mathrm{D}$ and calcium in patients suffering from migraine dramatically reduced frequency and severity of migraine ${ }^{[11,12]}$. Improvement of headache symptoms in eight vitamin D insufficient patients that had osteomalacia and tension-type headache (TTH) symptoms has been reported after they took vitamin D and calcium supplements for a short 
period of time ${ }^{[13]}$. In molecular level, Motaghi et al. ${ }^{[14]}$. have shown that vitamin $\mathrm{D}$ receptor polymorphisms are associated with migraine without aura and also headache severity.

However, there are no studies that compare vitamin D levels between control group and migraine patients with a large enough sample size and adjustments for age and sex. Also, there are no studies that compare the frequency and severity of headaches based on the vitamin D status. Therefore, in the view of above observations and paucity of data we investigated the vitamin D serum levels of migraine patients and compared it with a control group.

\section{Materials and Methods}

The present study entitled "To study the association of serum vitamin D levels with Migraine in Indian rural female population" was conducted in the Department of General Medicine during the period of 1 year. This observational case control study was performed on 150 patients (case group $n=100$ and matched control group $n=50$ ) attended General Medicine outpatient department.

\section{Inclusion criteria}

1. Patients who had given written and informed consent to take part in the study

2. Age group $18-50$ years

3. Patients with Chronic Headache

4. Diagnosis of Migraine based on history, physical examination, Guidelines according to International classification of Headache Disorders-II and ruling out secondary causes of headache with the help of relevant investigations

\section{Exclusion criteria}

1. Patients with conditions like hypertension, seizures, ocular disorders like refractory error \& Glaucoma, Intracranial space occupying lesions, head trauma, CVA, infections of sinuses, ear \& CNS, metabolic derangements and other plausible causes of headache.

2. Age $<18$ years or $>50$ years.

3. Patients who refused to give consent.

\section{Data collection and Measurement}

Demographic data including Age, BMI, Serum Vitamin D level and Level of Education was obtained from both groups. Patients were evaluated with regard to their Headache duration and Headache frequency and filled out the migraine severity scale (MIGSEV). It is a simple severity scale which categorized patients in three groups of intensity; mild, moderate, and severe. This instrument is highly reliable, reproducible, and sensitive ${ }^{[15]}$. To measure serum vitamin D level $3 \mathrm{~mL}$ of venous blood was drawn from each participant and immediately centrifuged. Serum samples were then frozen and kept at minus 70 degrees centigrade. Then, samples for plasma levels of 25-hydroxy vitamin D were analyzed with liquid chromatographytandem mass spectrometry (LC/MS/MS) method.

Based on previous studies and reports of Institute of Medicine (IOM), we considered serum levels of 25-hydroxy vitamin D of $>20,10-20$, and $<10 \mathrm{ng} / \mathrm{mL}$ as normal, insufficient, and deficient, respectively ${ }^{[16]}$.

\section{Statistical analysis}

We analyzed our data with the SPSS software (version 18.0, Chicago, IL, USA). Mann-Whitney $U$ test was used for the comparison of quantitative variables between two groups, since our data was not normally distributed. The sample size achieved $80 \%$ of the statistical power. Confidence level and level of significance were fixed at $95 \%$ and $5 \%$ respectively.

\section{Results}

Table 1: Mean values of age, serum Vit. D and BMI among cases and controls

\begin{tabular}{|c|c|c|c|}
\hline Variables & Cases $(\mathbf{N}=\mathbf{1 0 0})$ & Controls $(\mathbf{N}=\mathbf{5 0})$ & p - value \\
\hline Age $($ Mean \pm SD) & $34.54 \pm 1.37$ & $33.17 \pm 1.19$ & 0.292 \\
\hline Serum Vit. D & $13.12 \pm 0.98$ & $13.41 \pm 0.19$ & 0.078 \\
\hline BMI & $26.4 \pm 1.21$ & $25.8 \pm 1.53$ & 0.096 \\
\hline
\end{tabular}

Test applied: Student t-test

Table 2: Demographic distribution of study participants

\begin{tabular}{|c|c|c|}
\hline Variables & Cases N = 100 (\%) & Controls N = 50 (\%) \\
\hline \multicolumn{3}{|c|}{ Age groups } \\
\hline Less than 30 years & $42(42)$ & $27(54)$ \\
\hline More than 30 years & $58(58)$ & $23(46)$ \\
\hline \multicolumn{3}{|c|}{ Level of education } \\
\hline Below high school & $43(43)$ & $22(44)$ \\
\hline Above high school & $57(57)$ & $28(56)$ \\
\hline
\end{tabular}

Table 3: Distribution of cases according to headache frequency and duration

\begin{tabular}{|c|c|}
\hline Variables & Cases N = 100 \\
\hline Frequency of headache (Per month) & \\
\hline More than 10 & $58(58)$ \\
\hline Less than 10 & $42(42)$ \\
\hline Duration of headache (Per hour) & \\
\hline $4-12$ & $36(36)$ \\
\hline $12-24$ & $21(21)$ \\
\hline $24-72$ & $16(16)$ \\
\hline
\end{tabular}

Table 4: Distribution of different feature of migraine among cases

\begin{tabular}{|c|c|}
\hline Variables & Cases $N=100(\%)$ \\
\hline \multicolumn{2}{|c|}{ Intensity of pain } \\
\hline Mild & $9(9)$ \\
\hline Moderate & $28(28)$ \\
\hline Intense & $41(41)$ \\
\hline Very intense & $22(22)$ \\
\hline \multicolumn{2}{|c|}{ Level of nausea } \\
\hline None & $16(16)$ \\
\hline Mild & $39(39)$ \\
\hline Intense & $23(23)$ \\
\hline Vomiting & $22(22)$ \\
\hline \multicolumn{2}{|c|}{ Level of disability } \\
\hline None & $7(7)$ \\
\hline Mild & $34(34)$ \\
\hline Marked & $21(21)$ \\
\hline Confined to bed & $38(38)$ \\
\hline \multicolumn{2}{|c|}{ Level tolerability } \\
\hline Tolerable & $19(19)$ \\
\hline Barely Tolerable & $48(48)$ \\
\hline Intolerable & $33(33)$ \\
\hline \multicolumn{2}{|c|}{ MIGSEV total } \\
\hline Low & $17(17)$ \\
\hline Intermediate & $44(44)$ \\
\hline High & $39(39)$ \\
\hline
\end{tabular}


Table 5: Distribution of mean serum vitamin D levels according to demographics

\begin{tabular}{|c|c|c|c|c|}
\hline \multicolumn{5}{|c|}{ Mean serum vitamin D levels } \\
\hline Variables & $\begin{array}{l}\text { Controls } \\
(\mathbf{N}=50)\end{array}$ & $\begin{array}{c}\text { p - } \\
\text { value }\end{array}$ & $\begin{array}{c}\text { Cases } \\
(\mathbf{N}=100)\end{array}$ & $\begin{array}{c}\text { p - } \\
\text { value }\end{array}$ \\
\hline \multicolumn{5}{|c|}{ Age groups } \\
\hline Less than 30 years & $13.18 \pm 0.36$ & \multirow{2}{*}{0.843} & $13.02 \pm 0.76$ & \multirow{2}{*}{0.711} \\
\hline More than 30 years & $13.85 \pm 0.11$ & & $13.51 \pm 0.19$ & \\
\hline \multicolumn{5}{|c|}{ Level of education } \\
\hline Below high school & $13.11 \pm 0.71$ & \multirow{2}{*}{0.631} & $13.90 \pm 0.38$ & \multirow{2}{*}{0.881} \\
\hline Above high school & $13.32 \pm 0.62$ & & $13.24 \pm 0.81$ & \\
\hline
\end{tabular}

Test applied: Student t-test

\section{Discussion}

Based on our results, there was no significant difference in $25(\mathrm{OH}) \mathrm{D}$ plasma levels between cases and controls. Our analysis also did not show any relationship between 25(OH)D plasma levels and the severity of headaches among patients. Vitamin D deficiency has been defined based on various references. In most of the studies, $25(\mathrm{OH}) \mathrm{D}$ plasma levels lower than $10 \mathrm{ng} / \mathrm{mg}$ are considered deficient ${ }^{[17]}$, but defining he threshold for the levels of vitamin D insufficiency is a controversial issue ${ }^{[18,19]}$.

IOM recommended the levels of $20 \mathrm{ng} / \mathrm{mL}$ ( $50 \mathrm{nmol} / \mathrm{liter})$ covering the requirements of at least $97.5 \%$ of the population and this critical level will be useful for clinicians for patients' management [1]. Also, most of the studies reported that high majority of complications related to low levels of vitamin D such as hypoparathyodism, bone fractures, and multiple sclerosis are becoming at levels below $(20 \mathrm{ng} / \mathrm{mL})^{[20]}$.

The vitamin D plasma level can be measured by different laboratory methods including chemiluminescence assay, radioimmunoassay (RIA), and enzyme-linked immunosorbent assay (ELISA). Different methods can lead to significantly different reported levels of vitamin D in the same sample population. Inter-method variability of the $25(\mathrm{OH}) \mathrm{D}$ plasma levels can impact on further analysis of data from different studies. Data standardization is of great importance when different methods are used ${ }^{[21]}$.

Kjaergaard et al. ${ }^{[22]}$. In a cross-sectional study with a large sample concluded that vitamin D is not related to migraine. The latter, however, is limited as it has used a questionnaire to identify patients rather than identifying them clinically. Questionnaires may miss the patients or over diagnose people with migraine. Also, in this study, the relationship between severity and frequency of headaches and vitamin D is not evaluated. Our results did not show any relation between vitamin $\mathrm{D}$ and either severity of the headaches or their frequency.

Some studies have suggested that higher latitudes are associated with more sever and frequent headaches and therefore can originate from lower $25(\mathrm{OH}) \mathrm{D}$ plasma levels due to diminished sun exposure. This conclusion, however, is not totally reliable as there are regions with lower latitudes and worse vitamin D status. It can be assumed that vitamin D insufficiency may be caused by a multiple factors and latitude alone may not be responsible for lower $25(\mathrm{OH}) \mathrm{D}$ plasma levels. Seasonal changes in $25(\mathrm{OH}) \mathrm{D}$ plasma levels are reported in the literature ${ }^{[18]}$.

Thys-Jacobs reported dramatic reduction in frequency and duration of headaches after supplemental vitamin D administration. However, these results were from small case reports in two premenopausal and two postmenopausal women without control group [24, 25]. Despite these results we did not find any relation between $25(\mathrm{OH}) \mathrm{D}$ plasma levels and menstrual related aggravation of headaches. The therapeutic effect of vitamin D supplementation is thought to be due to higher absorption of magnesium; however, these treatments were accompanied by calcium supplements also and the results could be attributed to both vitamin D and calcium or even the synergetic effect of the treatment. Prakesh et al. ${ }^{[13]}$. reported positive effects of vitamin D and calcium supplements in tension type headache (TTH) patients. Beneficial outcomes of optimal 25(OH)D levels for TTH patients are also suggested by Keargaard et al. ${ }^{[22]}$.

Prakash et al. ${ }^{[13]}$. reported high levels of parathyroid hormone $(\mathrm{PTH})$ in migraine patients which could be due to secondary hyperparathyroidism that was treated by optimal levels of vitamin D supplement. The role of endothelial dysfunction and also the role of nitric oxide (NO) through vasodilatation as triggers for migraine headaches have been well established ${ }^{[23,24]}$. There are also studies, claiming that there are higher levels of parathyroid hormone in the systemic circulation of patients with heart failure, which is associated with endothelial dysfunction ${ }^{[25]}$. Also, it is stated that PTH up regulates the activity of the endothelial nitric oxide synthase NOS system through protein kinase pathways ${ }^{[26]}$.

On the other hand, vitamin deficiency can cause secondary hyperparathyroidism. However, whether or not the rise of PTH in this phenomenon contributes to worse migraine headaches through NO release and endothelial dysfunction is a matter of debate that needs further study.

Knutsen et al. ${ }^{[27]}$. Stated that vitamin D status has a much stronger relationship with headache rather than either musculoskeletal pain or fatigue. Our results did not reveal any relationship between the severity of the vitamin $D$ deficiency and severity of the headaches. Also, 25(OH)D plasma levels were not different between MIGSEV items (nausea, intensity of pain, pain tolerability, and disability). The relationship between age and severity of vitamin D deficiency was established by Knutsen et al. ${ }^{[27]}$. We found no relation between the age and levels of 25(OH)D. Also, according to our results, vitamin $\mathrm{D}$ level was not related to level of education.

\section{Conclusion}

The prevalence of vitamin D deficiency is roughly similar between cases and controls and between matching age groups. This suggests a high prevalence of vitamin D deficiency in both healthy population and migraine patients which implies a common underlying cause. It seems appropriate to conduct population-based observational studies to better assess the role of vitamin D in incidence, severity, and treatment of migraine headaches.

\section{References}

1. Holick MF. Vitamin D status: Measurement, interpretation, and clinical application. Ann Epidemiol 2009;19(2):73-8.

2. Holick MF. Resurrection of vitamin D deficiency and rickets. J Clin Invest 2006;116(8):2062-72.

3. Holick MF, Binkley NC, Bischoff-Ferrari HA, Gordon CM, Hanley DA, Heaney RP et al. Evaluation, treatment, and prevention of vitamin D deficiency: An Endocrine Society clinical practice guideline. J Clin Endocrinol Metab 2011;96(7):1911-30. 
4. Adorini L, Penna G. Control of autoimmune diseases by the vitamin $\mathrm{D}$ endocrine system. Nat Clin Pract Rheumatol 2008;4(8):404-12.

5. Talmor Y, Golan E, Benchetrit S et al. Calcitriol blunts the deleterious impact of advanced glycation end products on endothelial cells. Am J Physiol Renal Physiol 2008;294(5):F1059-F1064.

6. Baroni E, Biffi M, Benigni F et al. VDR-dependent regulation of mast cell maturation mediated by 1,25 dihydroxyvitamin D3. J Leukoc Biol 2007;81(1):25062.

7. Suzuki Y, Ichiyama T, Ohsaki A, Hasegawa S, Shiraishi M, Furukawa S. Anti-inflammatory effect of $1 \alpha$, 25- dihydroxy vitamin D3 in human coronary arterial endothelial cells: implication for the treatment of Kawasaki disease. J Steroid Biochem Mol Biol 2009;113(1-2):134-38.

8. Straube S, Andrew Moore R, Derry S, McQuay HJ. Vitamin D and chronic pain 2009;141(1-2):10-13.

9. Evans R. Expert opinion: What causes migraine, which physician explanation do patients prefer and understand? Headache 2009;49(10):1536-40.

10. Wheeler S. Vitamin D deficiency in chronic migraine. Headache 2008;48:S52-S53.

11. Thys-Jacobs S. Alleviation of migraines with therapeutic vitamin $\mathrm{D}$ and calcium. Headache 1994;34(10):590-92.

12. Thys-Jacobs S. Vitamin D and calcium in menstrual migraine. Headache 1994;34(9):544-46.

13. Prakash S, Shah ND. Chronic tension-type headache with vitamin D deficiency: Casual or causal association? Headache 2009;49(8):1214-22.

14. Motaghi M, Haghjooy Javanmard S, Haghdoost F, Tajadini M, Saadatnia M, Rafiee L, Zandifar A. Relationship between vitamin D receptor gene polymorphisms and migraine without aura in an Iranian population. Biomed Res Int 2013;2013:351942.

15. Buse DC, Loder EW, Gorman JA et al. Sex differences in the prevalence, symptoms, and associated features of migraine, probable migraine and other severe headache: Results of the American Migraine Prevalence and Prevention (AMPP) Study. Headache 2013;53(8):127899.

16. Thacher TD, Clarke BL. Vitamin D insufficiency. Mayo Clin Proc 2011;86(1):50-60.

17. Ross AC, Manson JE, Abrams SA, Aloia JF, Brannon PM, Clinton SK et al. The report on dietary reference intakes for calcium and vitamin D from the Institute of Medicine: What clinicians need to know. J Clin Endocrinol Metab 2011;96(1):53-8.

18. Rosen CJ, Abrams SA, Aloia JF et al. IOM committee members respond to Endocrine Society vitamin D guideline. J Clin Endocrinol Metab 2012;97(4):11461152.

19. Mithal A, Wahl DA, Bonjour JP et al. Global vitamin D status and determinants of hypovitaminosis D. Osteoporos Int 2009;20(11):1807-20.

20. Holick MF. Vitamin D deficiency. N Engl J Med 2007;357(3):266-81.

21. Wallace AM, Gibson S de la Hunty A, Lamberg-Allardt C, Ashwell M. Measurement of 25-hydroxyvitamin D in the clinical laboratory: Current procedures, performance characteristics and limitations. Steroids 2010;75(7):477-88.
22. Kjaergaard M, Eggen AE, Mathiesen EB, Jorde R. Association between headache and serum 25hydroxyvitamin D. The Troms $\varnothing$ Study: Troms $\varnothing$ 6. Headache 2012;52(10):1499-505.

23. Napoli R, Guardasole V, Zarra E et al. Vascular smooth muscle cell dysfunction in patients with migraine. Neurology 2009;72(24):2111-14.

24. Vanmolkot FH, De Hoon JN. Endothelial function in migraine: a cross-sectional study. BMC Neurology 2010;10:119.

25. Loncar G, Bozic B, Dimkovic S et al. Association of increased parathyroid hormone with neuroendocrine activation and endothelial dysfunction in elderly men with heart failure. J Endocrinol Invest 2011;34(3):7885.

26. Rashid G, Bernheim J, Green J, Benchetrit S. Parathyroid hormone stimulates the endothelial nitric oxide synthase through protein kinase A and C pathways. Nephrol Dial Transplant 2007;22(10):283137.

27. Knutsen KV, Brekke M, Gjelstad S, Lagerløv P. Vitamin D status in patients with musculoskeletal pain, fatigue and headache: a cross-sectional descriptive study in a multi-ethnic general practice in Norway. Scand J Prim Health Care 2010;28(3):166-71. 